\title{
Bactérias entéricas presentes em amostras de água e camarão marinho Litopenaeus vannamei oriundos de fazendas de cultivo no Estado do Ceará, Brasil
}

\author{
Enteric bacteria in water samples and marine shrimp Litopenaeus vannamei cultured in the \\ state of Ceará, Brazil
}

Lucélia Sabóia PARENTE'; Renata Albuquerque COSTA²; Gustavo Hitzschky Fernandes VIEIRA ${ }^{3}$; Eliane Moura Falavina dos REIS ${ }^{4}$; Ernesto HOFER ${ }^{4}$; Antonio Adauto FONTELES ${ }^{1}$; Regine Helena Silva dos Fernandes VIEIRA ${ }^{1}$

\author{
${ }^{1}$ Instituto de Ciências do Mar da Universidade Federal do Ceará, Fortaleza-CE, Brasil \\ ${ }^{2}$ Doutoranda em Engenharia de Pesca da Universidade Federal do Ceará , Fortaleza-CE, Brasil \\ ${ }^{3}$ Universidade Estadual Vale do Acaraú, Sobral - CE, Brasil \\ ${ }^{4}$ Instituto Oswaldo Cruz, Rio de Janeiro - RJ, Brasil
}

\begin{abstract}
Resumo
Foram realizados a quantificação de coliformes totais (CT) e termotolerantes (CTT), isolamento e identificação de coliformes, e pesquisa de Salmonella em 28 amostras de água e 28 de camarão da espécie Litopenaeus vannamei, oriundas de duas fazendas de cultivo localizadas no Estado do Ceará, Brasil. Nenhuma amostra de água apresentou índice de CTT acima do limite de $2.500 / 100 \mathrm{~mL}$ preconizado pela legislação para águas salobras destinadas ao cultivo de organismos para fins de consumo. O Número Mais Provável (NMP/g) de CTT das amostras de camarão variou de $<3$ a 2,9 $\times 10^{4}$. A maior frequência de isolamento de coliformes nas amostras de água e camarão foi a da espécie Escherichia coli. Em apenas três (5,35\%), das 56 amostras analisadas, foi detectada a presença de Salmonella sorovar Newport e $S$. Saintpaul. Apesar do baixo índice de CTT e da baixa incidência de salmonela, a presença dessas bactérias entéricas em ambientes de cultivo de peneídeos é preocupante, uma vez que podem provocar infecções em humanos.
\end{abstract}

Palavras-chave: Enterobactérias. Água. Camarão.

\begin{abstract}
Samples of water $(\mathrm{n}=28)$ and Litopenaeus vannamei $(\mathrm{n}=28)$ from two shrimp farms in Ceará state, Brazil were evaluated for total coliforms (TC), total thermotolerant coliforms (TTC), coliform species diversity and Salmonella. No water sample presented TTC levels above the maximum level (2,500 MPN/100 mL) established by regulation for brackish water aquaculture producing seafood for human consumption. The most probable number (MPN) of TTC in shrimp samples ranged from $<3$ to $2.9 \times 10^{4} \mathrm{CFU} / \mathrm{g}$. The coliform species most frequently isolated from water and shrimp was Escherichia coli. Only three (5.35\%) of the 56 samples tested were positive for Salmonella (Newport and Saintpaul serovars). In spite of the low TTC levels observed, the presence of potentially pathogenic enteric bacteria in shrimp culture is a disquieting finding.
\end{abstract}

Keywords: Enteric bacteria. Water. Shrimp.

\section{Introdução}

As bactérias entéricas representam um dos principais indicadores sanitários para camarões cultivados e são utilizadas como critérios de qualidade por órgãos nacionais ${ }^{1,2}$ e pela Comunidade Europeia, que é um dos principais importadores do camarão cultivado no Brasil ${ }^{3}$.

Norhana et al. ${ }^{4}$ afirmam que o comércio internacional de camarão vem sendo ampliado, facilitando a introdução de patógenos em novas áreas geográficas e em diferentes comunidades humanas. Para os autores, sob o ponto de vista da saúde pública, a produção de camarão livre de microrganismos patogênicos está se tornando uma preocupação mundial. Nesse contexto,

Correspondência para :

Regine Helena Silva dos Fernandes Vieira

Laboratório de Microbiologia Ambiental e do Pescado do Instituto de

Ciências do Mar (LABOMAR)

Avenida Abolição 3207, Fortaleza-Ceará; CEP: 60165-081

e-mail: regine@labomar.ufc.br

Recebido: 05/04/2010

Aprovado: 09/12/2010 
a pesquisa de bactérias de origem fecal em áreas de cultivo de peneídeos reveste-se de importância, uma vez que essas bactérias são consideradas indicadoras de contaminação fecal e, por conseguinte, de patógenos veiculados a dejetos fecais ${ }^{5}$.

Segundo Huss ${ }^{6}$, as enterobactérias podem ocorrer em pescado como resultado de contaminação fecal em decorrência da poluição das águas naturais ou de ambientes aquáticos, onde estes microrganismos podem sobreviver durante um longo período. Desse modo, a qualidade bacteriológica do ambiente de cultivo pode concorrer para contaminação dos organismos aquáticos. Para Gonçalves ${ }^{7}$ o conhecimento da microbiota do habitat do pescado torna possível a aplicação de medidas a fim de evitar um índice elevado de bactérias deterioradoras e eliminar os riscos à saúde do consumidor.

Dentre as bactérias entéricas, o grupo coliforme destaca-se como um indicador microbiológico amplamente utilizado para avaliação higiênico-sanitária de alimentos e vem sendo isolado de diferentes componentes de sistemas de carcinicultura, como sedimento ${ }^{8}$, água e camarão ${ }^{9}$

O gênero Salmonella também merece destaque como indicador de qualidade sanitária em pescado. Segundo Argôlo Filho ${ }^{10}$, a excreção da Salmonella pelas das fezes de animais homeotermos, pode contaminar água, solo, outros animais e alimentos. Os animais cultivados podem, portanto, sofrer infecção pelo contato direto com fezes, água e alimentos contaminados.

Muitos estudos relatam a incidência de salmonela em alimentos de origem marinha ${ }^{11,12,13}$ e alertam para o perigo potencial desse patógeno como causador de gastroenterites em humanos. De acordo com Hofer, Silva Filho e Reis ${ }^{14}$, a severidade da doença provocada por salmonela depende da virulência da estirpe e das condições do hospedeiro humano.

Diante do exposto, objetivou-se no presente estudo pesquisar a ocorrência de bactérias entéricas em amostras de água e camarão marinho Litopenaeus vannamei provenientes de duas fazendas de cultivo no Estado do Ceará, por meio da quantificação e identificação de coliformes e detecção de Salmonella.

\section{Material e Método}

Amostragem. Foram analisadas 28 amostras de água e 28 de camarão durante o período de março a outubro de 2004, coletadas em quatro viveiros de duas fazendas de camarão (fazenda 1 - V1 e V2, fazenda 2 - V3 e V4) localizados no estuário do rio Coreaú, litoral oeste do Estado do Ceará. Essa região possui características climáticas compatíveis às da região do semiárido nordestino, com distribuição da estação chuvosa nos meses de fevereiro a maio. As amostras de água foram coletadas em garrafas âmbar, com capacidade para um litro, previamente esterilizadas. Os camarões foram obtidos com emprego de redes e acondicionados em sacos plásticos estéreis. Todas as amostras foram mantidas em recipiente isotérmico até o início das análises microbiológicas.

Preparação das Amostras. Para a preparação das amostras de água e camarão, destinadas a análise de coliformes totais e termotolerantes, foi realizada diluição de $1 \mathrm{~mL}$ e $50 \mathrm{~g}$ em $9 \mathrm{~mL}$ e $450 \mathrm{~mL}$ de solução salina, respectivamente, obtendo-se a diluição de 10', a partir da qual foi feita a diluição decimal seriada de $10^{-2}$ retirando-se $1 \mathrm{~mL}$ e homogeneizando-o em 9 $\mathrm{mL}$ de salina, e assim sucessivamente até a diluição de $10^{-4}$.

\section{Quantificação de Coliformes Totais (CT) e Termo-} tolerantes (CTT). A determinação do Número Mais Provável (NMP) de CT e CTT foi feita de acordo com técnica de fermentação em tubos múltiplos ${ }^{15}$. Para o cálculo do NMP de CT e CTT foram escolhidas as séries críticas dos tubos positivos na prova confirmatória e prova de determinação de CTT, respectivamente, e lidas na tabela de Hoskins citada em Blodgett ${ }^{16}$. $O$ valor da série crítica foi multiplicado pela diluição média e expresso em NMP/100 mL para as amostras 
de água. Para as amostras de camarão, o valor da série crítica foi multiplicado pela diluição média e dividido por 100, sendo expresso em NMP/g.

Isolamento e Identificação de Coliformes. As colônias, com características de coliformes crescidas no meio Agar Eosina Azul de Metileno (EMB), foram isoladas em Agar Triptona Soja (TSA) e submetidas à identificação bioquímica a partir do grupo de testes do $\mathrm{IMViC}^{15}$. Em todos os isolados foram realizadas as provas de produção de indol, vermelho de metila, produção de acetoína em Voges-Proskaeur, utilização de citrato, fermentação da lactose, produção de $\mathrm{H}_{2} \mathrm{~S}$ e motilidade.

Pesquisa de Salmonella. Foram realizadas as etapas de pré-enriquecimento, enriquecimento seletivo e triagem bioquímica, de acordo com Wallace e Hammack ${ }^{17}$. Para a realização da etapa de pré-enriquecimento foram filtrados $5 \mathrm{~L}$ de água em papel de filtro esterilizado, que foi incubado em $225 \mathrm{~mL}$ de Caldo Lactosado (CL), e homogeneizados $25 \mathrm{~g}$ de camarão em $225 \mathrm{~mL}$ de $\mathrm{CL}$, com incubação a $35{ }^{\circ} \mathrm{C} / 24 \mathrm{~h}$. Na etapa de enriquecimento seletivo, foram retiradas alíquotas de $1 \mathrm{~mL}$ e $0,1 \mathrm{~mL}$ do CL e inoculadas em 10 $\mathrm{mL}$ de caldo Tetrationato $\left(43{ }^{\circ} \mathrm{C} / 24 \mathrm{~h}\right)$ e em $9 \mathrm{~mL}$ de caldo Rappaport $\left(42{ }^{\circ} \mathrm{C} / 24 \mathrm{~h}\right)$, respectivamente. Os tubos positivos foram plaqueados em ágar Hektoen e ágar MacConkey com incubação por 24 h/ 35-37 ${ }^{\circ} \mathrm{C}$. Com as colônias características de Salmonella foram realizadas triagens em ágar tríplice açúcar ferro (TSI) e ágar lisina ferro (LIA). A partir dessas triagens, foram selecionadas cepas com perfil bioquímico compatível com o gênero Salmonella destinadas à realização da sorologia com o antissoro somático polivalente (poli O:H). A caracterização ao nível de sorovar foi realizada no Laboratório de Enterobactérias do Instituto Oswaldo Cruz (FioCruz) no Rio de Janeiro.

\section{Resultados e Discussão}

Os resultados referentes ao NMP de CT e CTT das amostras de água e camarão das duas fazendas encon- tram-se descritos na tabela 1 . Nenhuma amostra de água apresentou índice de CTT superiores ao limite de 2.500/100 mL preconizado pela Resolução 357 de 2005 do Conselho Nacional do Meio Ambiente $\mathrm{CONAMA}^{2}$ para águas salobras destinadas ao cultivo de organismos para fins de consumo.

A variação de CT e CTT observada nos quatro viveiros pesquisados sugere que o material orgânico recebido pelos tanques de cultivo é variável. Considerando que para Vieira et al. ${ }^{18}$ a presença de coliformes está relacionada a uma maior concentração de matéria orgânica, pode-se sustentar a assertiva de que os viveiros estão recebendo aportes de nutrientes que concorrem para proliferação e manutenção de coliformes na coluna d'água.

Nas amostras de camarão foi observada uma variação de CTT/g de $<3$ a 2,9 x 104. Valores de NMP de CTT/g superiores a 1.000 foram observadas em $6(21,42 \%)$ amostras. A legislação vigente ${ }^{1}$ não estipula limites para coliformes termotolerantes a 45 ${ }^{\circ} \mathrm{C}$ em camarões in natura, no entanto, é sabido que um dos maiores importadores do camarão cultivado no Brasil é a Comunidade Europeia (CE) que por meio da "Comission Decision" de 15 de dezembro de 1992, limita o índice de Escherichia coli em camarão em $100 \mathrm{NMP} / \mathrm{g}$. Apesar de não ter sido feita a quantificação de E. coli, a presença de CTT nas amostras de camarão pode ser considerada como indicadora de contaminação de origem fecal. Para Muratori et al. ${ }^{19}$, a ocorrência de coliformes termotolerantes em pescado indica que os mesmos foram capturados em ambientes com elevados índices de contaminação bacteriana.

Reis et al. ${ }^{20}$, em estudo sobre as condições higiênico-sanitárias de camarões, encontraram índices de $\mathrm{NMP} / \mathrm{g}$ de CT e CTT semelhantes aos do presente estudo, com uma variação de $<3$ e $>1.100 \mathrm{NMP} / \mathrm{g}$ e $<3$ e $460 \mathrm{NMP} / \mathrm{g}$, respectivamente.

Apesar de não haver na legislação brasileira limites para CT em ambientes de cultivo de peneídeos, 
Tabela 1 - Número Mais Provável (NMP/100 mL e NMP/g) de Coliformes Totais (CT) e Termotolerantes (CTT) em amostras de água e camarão provenientes de viveiros de cultivo do camarão Litopenaeus vannamei

\begin{tabular}{|c|c|c|c|c|c|c|c|c|}
\hline \multirow{4}{*}{ A. } & \multicolumn{8}{|c|}{ Água (NMP/100mL) } \\
\hline & \multicolumn{4}{|c|}{ Fazenda 1} & \multicolumn{4}{|c|}{ Fazenda 2} \\
\hline & \multicolumn{2}{|c|}{ Viveiro 1} & \multicolumn{2}{|c|}{ Viveiro 2} & \multicolumn{2}{|c|}{ Viveiro 3} & \multicolumn{2}{|c|}{ Viveiro 4} \\
\hline & $\mathrm{CT}$ & CTT & $\mathrm{CT}$ & CTT & $\mathrm{CT}$ & CTT & $\mathrm{CT}$ & CTT \\
\hline 1 & $<1,8$ & $<1,8$ & $<1,8$ & $<1,8$ & $1,4 \times 10^{4}$ & $<1,8$ & $1,8 \times 10^{5}$ & $1,8 \times 10^{3}$ \\
\hline 2 & $2,1 \times 10^{3}$ & $<1,8$ & $7,8 \times 10^{2}$ & $7,8 \times 10^{2}$ & $1,4 \times 10^{3}$ & $4,0 \times 10^{2}$ & $2,7 \times 10^{3}$ & $4,5 \times 10^{2}$ \\
\hline 3 & $7,8 \times 10^{2}$ & $<1,8$ & $2,4 \times 10^{3}$ & $2,4 \times 10^{3}$ & $4,7 \times 10^{3}$ & $1,1 \times 10^{3}$ & $<1,8$ & $<1,8$ \\
\hline 4 & $3,7 \times 10^{2}$ & $<1,8$ & $6,8 \times 10^{2}$ & $<1,8$ & $<1,8$ & $<1,8$ & $4,5 \times 10^{2}$ & $2,0 \times 10^{2}$ \\
\hline 5 & $<1,8$ & $<1,8$ & $9,3 \times 10^{2}$ & $<1,8$ & $<1,8$ & $<1,8$ & $<1,8$ & $<1,8$ \\
\hline 6 & $<1,8$ & $<1,8$ & $<1,8$ & $<1,8$ & $7,8 \times 10^{3}$ & $<1,8$ & $2,0 \times 10^{2}$ & $<1,8$ \\
\hline \multirow[t]{3}{*}{7} & $<1,8$ & $<1,8$ & $8,1 \times 10^{4}$ & $<1,8$ & $1,1 \times 10^{3}$ & $2,0 \times 10^{2}$ & $2,0 \times 10^{2}$ & $<1,8$ \\
\hline & \multicolumn{8}{|c|}{ Camarão (NMP/g) } \\
\hline & \multicolumn{4}{|c|}{ Fazenda 1} & \multicolumn{4}{|c|}{ Fazenda 2} \\
\hline \multirow[t]{2}{*}{$\mathrm{A}$} & \multicolumn{2}{|c|}{ Viveiro 1} & \multicolumn{2}{|c|}{ Viveiro 2} & \multicolumn{2}{|c|}{ Viveiro 3} & \multicolumn{2}{|c|}{ Viveiro 4} \\
\hline & $\mathrm{CT}$ & CTT & $\mathrm{CT}$ & CTT & CT & CTT & $\mathrm{CT}$ & CTT \\
\hline 1 & $1,5 \times 10^{4}$ & $1,1 \times 10^{4}$ & $1,1 \times 10^{4}$ & $4,6 \times 10^{3}$ & $2,4 \times 10^{4}$ & $2,1 \times 10^{4}$ & $2,9 \times 10^{4}$ & $4,6 \times 10^{3}$ \\
\hline 2 & $2,4 \times 10^{3}$ & $4,3 \times 10^{2}$ & $4,6 \times 10^{3}$ & $4,6 \times 10^{3}$ & $>1,1 \times 10^{3}$ & $1,5 \times 10$ & $>1,1 \times 10^{3}$ & $4,3 \times 10$ \\
\hline 3 & $1,5 \times 10^{2}$ & $3,8 \times 10$ & $1,1 \times 10^{5}$ & $4,6 \times 10^{3}$ & $4,3 \times 10^{2}$ & $<3$ & $1,5 \times 10^{2}$ & 9,2 \\
\hline 4 & $>1,1 \times 10^{3}$ & 3 & $2,7 \times 10^{3}$ & $2,8 \times 10^{2}$ & $2,9 \times 10^{2}$ & 43 & $2,4 \times 10^{3}$ & $3,8 \times 10^{2}$ \\
\hline 5 & $9,3 \times 10$ & 3,6 & $2,4 \times 10^{4}$ & $4,3 \times 10^{2}$ & $1,5 \times 10^{2}$ & $<3$ & $4,3 \times 10^{2}$ & $<3$ \\
\hline 6 & $2,1 \times 10^{2}$ & 3,6 & $7,5 \times 10$ & $2,3 \times 10$ & $2,4 \times 10^{2}$ & 93 & $2,1 \times 10$ & 3,6 \\
\hline 7 & 23 & $<3$ & $4,6 \times 10^{3}$ & $<3$ & $2,1 \times 10$ & $<3$ & $2,1 \times 10^{2}$ & $<3$ \\
\hline
\end{tabular}

* A.: Amostras

os achados do presente estudo estão de acordo como os de Álvares et al. ${ }^{21}$, que em pesquisa sobre as características higiênico-sanitárias e microbiológicas de pescado comercializado em São Paulo detectaram uma contaminação por CT variando de 3,6 a > $1.100 \mathrm{NMP} / g$. Os autores destacaram que mesmo não havendo limites legais para os índices de CT, a ocorrência dessas bactérias em alimento merece destaque, pois as mesmas não deixam de estar relacionadas a sua qualidade higiênico-sanitária.
Os valores de NMP de CT e CTT das amostras de camarão foram superiores aos das amostras de água (Tabela 1). É possível que isto ocorra porque o camarão além de concentrar os microrganismos em áreas menores que aquelas em água, também é mais rico em nutrientes representando um excelente substrato para colonização bacteriana, diferentemente da água que é considerada um pobre meio de cultivo para microrganismos. Resultados concordantes foram verificados por Fonseka ${ }^{22}$ e Putro et al. $^{23}$, que observaram uma 
contagem de coliforme mais elevada no camarão do que na água de cultivo.

Não foi observada uma variação significante entre os índices de NMP/100 mL de CT e CTT das amostras de água das fazendas 1 e 2. Entretanto, houve uma variação significativa entre as amostras de camarão das fazendas 1 e 2 no que tange a carga de CT e CTT/g (Tabela 2).
As análises estatísticas sugerem que as amostras de camarão da fazenda 2 apresentaram uma carga de coliforme significativamente superior às da fazenda 1 , apesar de não haver variação significativa na microbiota da água. Alguns fatores, observados apenas na fazenda 1, podem ter contribuído para esse achado, como a presença de mamíferos e de aves nas proximidades dos viveiros. Além disso, a qualidade bac-

Tabela 2 - Análise estatística dos índices de Número Mais Provável (NMP) de coliformes totais (CT) e termotolerantes (CTT) das fazendas 1 e 2

\begin{tabular}{|c|c|c|c|c|}
\hline & \multicolumn{2}{|c|}{ Água } & \multicolumn{2}{|c|}{ Camarão } \\
\hline & Fazenda 1 & Fazenda 2 & Fazenda 1 & Fazenda 2 \\
\hline & \multicolumn{4}{|c|}{ Coliformes totais } \\
\hline Média & 4,504 & 5,487 & 7,419 & 5,703 \\
\hline Variância & 14,392 & 14,294 & 5,675 & 3,806 \\
\hline Valor de $t$ & \multicolumn{2}{|c|}{0,825} & \multicolumn{2}{|c|}{2,408} \\
\hline Valor de P & \multicolumn{2}{|c|}{0,4143} & \multicolumn{2}{|c|}{0,0214} \\
\hline \multirow[t]{2}{*}{ Significância } & \multicolumn{2}{|c|}{ Não significante } & \multicolumn{2}{|c|}{ Significante } \\
\hline & \multicolumn{4}{|c|}{ Coliformes termotolerantes } \\
\hline Média & 1,791 & 2,541 & 4,698 & 2,851 \\
\hline Variância & 7,819 & 10,545 & 11,110 & 6,956 \\
\hline Valor de $t$ & \multicolumn{2}{|c|}{0,780} & \multicolumn{2}{|c|}{1,883} \\
\hline Valor de P & \multicolumn{2}{|c|}{0,4402} & \multicolumn{2}{|c|}{0,0680} \\
\hline Significância & \multicolumn{2}{|c|}{ Não significante } & \multicolumn{2}{|c|}{ Significante } \\
\hline
\end{tabular}

teriológica do sedimento pode ter influenciado na contaminação das amostras de camarão, uma vez que esses crustáceos são bentônicos. A verificação de que os coliformes totais e E. coli ocorrem no sedimento em quantidades significativamente superiores as da coluna d'água foi relatada por An, Kampbell e Breidenbach ${ }^{24}$.

Das 80 cepas de coliformes oriundas das amostras de água das duas fazendas, $55(68,75 \%)$ foram identificadas como E. coli, 13 (16,25\%) como Citrobacter spp., 10 (12,5\%) como Klebsiella spp e 2 (2,5\%) como Enterobacter spp. Foram isoladas 124 cepas de coliformes de todas as amostras de camarão analisadas, sendo 72 (58\%) E. coli, 26 (21\%) Enterobacter spp., 15 (12\%) Klebsiella e 11 (9\%) Citrobacter spp.

A distribuição de bactérias da família Enterobacteriaceae em viveiros de cultivo de organismos aquáticos foi relatada por Sivakami, Premkishore e Chandran ${ }^{25}$, que verificaram os coliformes E. coli, Enterobacter e Klebsiella como parte da microbiota exógena de ambientes de cultivo. Para os autores, a qualidade da água utilizada em aquicultura é refletida na microbiota dos organismos cultivados. Essa observação foi confirmada no presente estudo, uma vez que a composição bacteriológica da água foi semelhante a do camarão, com predominância da espécie E. coli, 
variando apenas na frequência de isolamento dos gêneros Citrobacter e Enterobacter.

Nesse contexto, Sugamar, Jawahar e Shanmugam ${ }^{26}$ isolaram bactérias patogênicas de um sistema de cultivo de camarão, verificando concomitantemente $E$. coli nas amostras de água e camarão analisadas. Os autores revelaram que deve haver um manejo adequado durante todo o ciclo de produção de camarão a fim de se evitar contaminações do pescado por patógenos bacterianos, minimizando, portanto, possíveis infecções nos consumidores desse tipo de produto.

Além do aporte de matéria orgânica, outro fator que pode concorrer para o isolamento de coliformes nos viveiros é a temperatura da água. Por serem mesófilas, as bactérias pertencentes a esse grupo têm sido isoladas de amostras de água de regiões tropicais ${ }^{27}$, podendo ocorrer, durante o verão, em reservatórios de países temperados ${ }^{28}$.

A prevalência de E. coli nos camarões está de acordo com Hatha, Maqbool e Kumar ${ }^{29}$, que pesquisaram a qualidade microbiológica de produtos oriundos de atividade de carcinicultura na Índia e verificaram a presença dessa enterobactéria em camarões crus.

Carvalho ${ }^{3}$ investigou as influências exógenas na qualidade bacteriológica da água, solo e camarão em fazendas de cultivo do Estado do Ceará e encontrou resultados semelhantes aos da presente pesquisa no que concerne ao isolamento de E. coli. $\mathrm{O}$ autor alerta que a presença de E. coli no ambiente de cultivo de peneídeos é preocupante, uma vez que essa espécie possui origem fecal tendo como habitat o trato intestinal dos animais de sangue quente e pecilotérmicos.

No que tange a pesquisa de Salmonella, foram identificadas apenas três cepas de todas as amostras (água e camarão). Duas estirpes, oriundas de uma amostra de água e camarão da fazenda 2 , foram confirmadas como o sorovar $S$. Saintpaul, e a terceira, proveniente de uma amostra de água da fazenda 1 , foi identificada como $S$. Newport. Desse modo, apenas uma amostra de camarão encontra-se fora dos padrões microbio- lógicos contemplados pela ANVISA ${ }^{1}$, que preconiza ausência de Salmonella em crustáceos in natura resfriados ou congelados não consumidos crus.

O gênero Salmonella possui mais de 2.000 sorovars $^{30}$. Dentre esses, os dois detectados na presente pesquisa (S. Saintpaul e $S$. Newport) já foram isolados de alimentos de origem marinha ${ }^{31}$.

Heinitz et al. ${ }^{32}$, em investigação sobre a ocorrência de Salmonella em alimentos marinhos destinados a alimentação humana, destacaram o sorovar $S$. Newport como o sexto mais frequente e alertaram que o mesmo vem sendo associado a doenças transmitidas por alimentos nos Estados Unidos.

A baixa ocorrência de Salmonella observada no presente estudo está de acordo como os resultados obtidos por Hatha \& $\mathrm{Rao}^{33}$, que relataram apenas uma amostra positiva para Salmonella de um total de 1.264 camarões crus analisados e, sugeriram que este fato pode estar relacionado à contaminação dos viveiros de cultivo por diferentes fontes, como a utilização de fertilizantes de origem animal não tratados. Outrossim, Dalsgaard et al. ${ }^{34}$ não detectaram salmonela em nenhuma das 158 amostras (água, sedimento, camarão, ração e fertilizante) coletadas em áreas de cultivo de camarão. Segundo os autores, a contaminação por salmonela pode ser resultante de processamento inadequado do camarão e não advém necessariamente dos viveiros de cultivo. Os camarões analisados na presente investigação não sofreram qualquer tipo de processamento, uma vez que foram coletados diretamente nas fazendas, desse modo, a presença desse patógeno pode ter sido decorrente da contaminação dos viveiros.

Bhaskar et al. ${ }^{8}$ encontraram dados discordantes com o da presente pesquisa quando da verificação da incidência de Salmonella em camarões cultivados. Os autores detectaram esse gênero bacteriano em todas as amostras de camarão pesquisadas e sugeriram que o mesmo faça parte da microbiota natural de ambientes destinados ao cultivo de peneídeos, destacando 
que as principais fontes que contribuem para a sua ocorrência nesses ambientes podem ser o sedimento, água e ração. Em pesquisa sobre a prevalência de bactérias de interesse sanitário em camarões cultivados da espécie Penaeus monodon, Bhaskar et al. ${ }^{9}$ também sustentaram a hipótese de que o gênero Salmonella pertença ao grupo de bactérias que ocorrem naturalmente em ambientes de cultivo de camarão, uma vez que não foi observada correlação entre a presença de coliformes e a incidência desses patógenos.

Por outro lado, os achados do presente estudo corroboram os de Shabarinath et al. ${ }^{35}$, que detectaram salmonela em camarões e afirmaram que esse grupo de patógenos entéricos pode ser encontrado em águas fluviais e sedimentos marinhos e estuarinos desde que haja alguma fonte de contaminação fecal, posto que seu habitat natural é o trato intestinal de animais homeotermos. Ainda nesse sentido, Koonse et al. ${ }^{36}$ afir-

\section{Referências}

1.BRASIL. Ministério da Saúde. Agência Nacional de Vigilância Sanitária. Resolução RDC no 12, de 12 de janeiro de 2001. Brasília: ANVISA, 2001.

2.BRASIL. Ministério da Saúde. Agência Nacional de Vigilância Sanitária. Resolução no 357 de 17 de março de 2005. Brasília: ANVISA, 2005.

3. CARVALHO, F. C. T. Influências exógenas na qualidade bacteriológica da água, solo e camarão (Litopenaeus vannamei), em quatro fazendas de camarão do Estado do Ceará. 2006. 87 p. Dissertação Mestrado em Ciências Marinhas Tropicais. Universidade Federal do Ceará. Ceará, 2006.

4.NORHANA, M. N. W.; POLLE, S. E.; DEETH, H. C.; DYKES, G. A. Prevalence, persistence and control of Salmonella and Listeria in shrimp and shrimp products: a review. Food Control, v. 21, p. 343-361, 2010.

5.MARTINS, C. V. B; VAZ, S. T.; MINOZZO, M. G. Aspectos sanitários de pescados comercializados em "pesque-pagues" de Toledo-PR. Higiene Alimentar, v. 16, n. 98, p. 51-56, 2002.

6.HUSS, H. H. Garantia da qualidade dos produtos da pesca. Roma: Organização das Nações Unidas para a Alimentação e Agricultura, 1997. 176 p. (Documento Técnico sobre as Pescas, n. 334).

7.GONÇALVES, P. M. R. O pescado e as bactérias do seu meio ambiente. Higiene Alimentar, v. 18, n. 116/117, p. 29-32, 2004.

8.BHASKAR, N.; SETTY, T. M. R.; REDDY, G. V. S.; MANOJ, Y. B.; ANANTHA, C. S.; RAGHUNATH, B. S.; ANTONY, J. M. Incidence of Salmonella in cultured shrimp Penaeus monodon. Aquaculture, v. 138, p. 257-266, 1995. mam que o gênero Salmonella não faz parte da microbiota natural do ambiente de cultivo de camarão, e sua ocorrência na aquicultura está relacionada com a concentração de bactérias fecais recebidas pelos viveiros.

\section{Conclusões}

Todas as amostras de água mostraram-se próprias para o cultivo de organismos aquáticos, uma vez que não apresentaram índices de CTT/100 mL superiores a 2.500; como não há legislação que preconize limites para coliformes termotolerantes em camarões in natura, os valores de NMP de CTT/g observados no presente estudo não podem ser usados como critério para avaliação da qualidade sanitária das amostras de camarão cultivado e a presença de Salmonella sovorar Saintpaul caracteriza como imprópria para o consumo uma $(3,57 \%)$ das 28 amostras de camarão analisadas.

9.BHASKAR, N.; SETTY, T. M. R.; MONDAL, S.; JOSEPH, M. A.; RAJU, C. V.; RAGHUNATH, B. S.; ANANTHA, C. $\mathrm{S}$. Prevalence of bacteria of public health significance in the cultured shrimp (Penaeus monodon). Food Microbiology, v. 15, p. 511-519, 1998.

10.ARGÔLO FILHO, R. C. A. Identificação, sorotipagem e diferenciação pela PCR-DGGE de sorotipos de Salmonella isolados de teiús criados em cativeiro. 2007. 96 p. Dissertação Mestrado em Genética e Biologia Molecular. Universidade Estadual de Santa Cruz, Ilhéus-BA. 2007.

11.CHENG, C. M.; LIN, W.; VAN, K. T.; PHAN, L.; TRAN, N. N.; FARMER, D. Rapid detection of Salmonella in foods using real-time PCR. Journal of Food Protection, v. 71, n. 12, p. 2436-2441, 2008.

12. ASAI, Y.; KANEKO, M.; OHTSUKA, K.; MORITA, Y.; KANEKO, S.; NODA, H.; FURUKAWA, I.; TAKATORI, K.; HARA-KUDO, Y. Salmonella prevalence in seafood imported into Japan. Journal of Food Protection, v. 71, n. 7, p. 1460-1464, 2008.

13. CARVALHO, F. C. T.; BARRETO, N. S. E.; REIS, C. M. F.; HOFER, E.; VIEIRA, R. H.S. F. Susceptibilidade antimicrobiana de Salmonella spp. isoladas de fazendas de carciniculturas no Estado do Ceará. Revista Ciência Agronômica, v. 40, n. 4, p. 549-556, 2009.

14.HOFER, E.; SILVA FILHO, S. J.; REIS, E. M. F. Prevalência de sorovares de Salmonella isolados de aves no Brasil. Pesquisa Veterinária Brasileira, v. 17, n. 2, p. 55-62, 1997.

15.FENG, P.; WEAGANT, S.D.; GRANT, M.A. Enumeration of Escherichia coli and the Coliform Bacteria. In: NEW HAMPSHIRE: FOOD AND DRUGS ADMINISTRATION, CENTER FOR FOOD SAFETY \& APPLIED NUTRITION. Bacteriological Analytical Manual. FDA/CFSAN, 2002. 
16.BLODGETT, R. Appendix 2: Most Probable Number from Serial Dilutions. In: NEW HAMPSHIRE: FOOD AND DRUGS ADMINISTRATION, CENTER FOR FOOD SAFETY \& APPLIED NUTRITION. Bacteriological Analytical Manual. FDA/CFSAN, 2006.

17. WALLACE, H. A; HAMMACK, T. S. Salmonella. In: NEW HAMPSHIRE: FOOD AND DRUGS ADMINISTRATION, CENTER FOR FOOD SAFETY \& APPLIED NUTRITION. Bacteriological Analytical Manual. FDA/CFSAN, 2005.

18.VIEIRA, R. H. S. F.; SILVA, A. I. M.; SOUSA, O. V.; HOFER, E.; VIEIRA, G. H. F.; SAMPAIO, S. S.; LIMA, E. A. Análise experimental sobre a viabilidade de Escherichia coli em água do mar. Arquivos de Ciências do Mar, v. 34, p. 43-48, 2001.

19.MURATORI, M. C. S.; COSTA, A. P. R. C.; VIANA, C. M.; RODRIGUES, P. C.; PODESTÁ JR., R. L. Qualidade sanitária de pescado "in natura". Higiene Alimentar, v. 18, n. 116/117, p. 50-54, 2004.

20. REIS, J. A.; HOFFMANN, P.; MARCOS, L. M.; TADDEI, F. G.; GONÇALVES, T. M. V.; HOFFMAN, F. L. Estudo higiênicosanitário dos camarões dulcíolas Macrobrachium amazonicum e M. jeslskii. Higiene Alimentar, v. 18, n. 116/117, p. 58-67, 2004 .

21.ÁLVARES, P. P.; MARTINS, L.; BORGHOFF, T.; SILVA, W. A.; ABREU, T. Q.; GONÇALVES, F. B. Análise das características higiênico-sanitárias e microbiológicas de pescado comercializado na grande São Paulo. Higiene Alimentar, v. 22 , n. 161 , p. $88-93,2008$.

22.FONSEKA, T. S. G. Microbial flora of pond cultured prawn (Penaeus monodon). FAO Fisheries Report, n. 401, p. 24-31, 1990. Supplement.

23.PUTRO, S.; ANGAWAIT, A. M.; FAWZYA, Y. N.; ARIYANI, F. Studies on the microbiology of farmed shrimp. FAO Fisheries Report, n. 401, p. 6-17, 1990

24.AN, Y-J.; KAMPBELL, D. H.; BREIDENBACH, G. P. Escherichia coli in water and sediments at lake marinas. Environmental Pollution, v. 120, n. 3, p. 771-778, 2002.

25.SIVAKAMI， R.; PREMKISHORE，G.; CHANDRAN， M. R. Occurrence and distribution of potentially pathogenic Enterobacteriaceae in carps and pond water in Tamil Nadu, India. Aquaculture Research, v. 27, p. 375-378, 1996.

26.SUGUMAR, G.; JAWAHAR, A. T.; SHANMUGAM, S. A. Human pathogenic bacteria in shrimp farming system. Indian Journal of Microbiology, v. 41, n. 4, p. 269-274, 2001.
27.BYAMUKAMA, D.; KANSIIME, F.; MACH, R. L.; FARNLEITNER, A. H. Determination of Escherichia coli contamination with chromocult coliform agar showed a high level of discrimination efficiency for differing fecal pollution levels in tropical waters of Kampala, Uganda. Applied and Environmental Microbiology, v. 66, n. 2, p. 864-868, 2000.

28.NOBLE, R. T.; MOORE, D. F.; LEECASTER, M. K.; MCGEE, C. D.; WEISBERG, S. B. Comparison of total coliform, fecal coliform, and enterococcus bacterial indicator response for ocean recreational water quality testing. Water Research, v. 37, p. 1637-1643, 2003.

29.HATHA, A. A. M.; MAQBOOL, T. K.; KUMAR, S. S. Microbial quality of shrimp products of export trade produced from aquacultured shrimp. International Journal of Food Microbiology, v. 82, p. 213-221, 2003.

30.KUMAR, H. S.; SUNIL, R.; VENUGOPAL, M. N.; KARUNASAGAR, I.; KARUNASAGAR, I. Detection of Salmonella spp. in tropical seafood by polymerase chain reaction. International Journal of Food Microbiology, v. 88, p. 91-95, 2003.

31.PONCE, E.; KHAN, A. A.; CHENG, C-M.; SUMMAGEWEST, C.; CERNIGLIA, C. E. Prevalence and characterization of Salmonella enterica serovar Weltevreden from imported seafood. Food Microbiology, v. 25, n. 1, p. 29-35, 2008.

32.HEINITZ, M. L.; RUBLE, R. D.; WAGNER, D. E.; TATINI, S. R. Incidence of Salmonella in fish and seafood. Journal of Food Protection, v. 63, n. 5, p. 579-592, 2000.

33. HATHA, A. A. M.; RAO, N. P. B. Bacteriological quality of individually quick-frozen (IQC) raw and cooked ready-to-eat shrimp produced from farm raised black tiger shrimp (Penaeus monodon). Food Microbiology, v. 15, p. 177-183, 1998.

34.DALSGAARD, A.; HUSS, H. H.; H-KITTIKUN, A.; LARSEN, J. L. Prevalence of Vibrio cholerae and Salmonella in a major shrimp production area in Thailand. International Journal of Food Microbiology, v. 28, n. 1, p. 101-113, 1995.

35.SHABARINATH, S.; SANATH KUMAR, H.; KHUSHIRAMANI, R.; KARUNASAGAR, I.; KARUNASAGAR, I. Detection and characterization of Salmonella associated with tropical seafood. International Journal of Food Microbiology, v. 114, n. 2, p. 227-33, 2007.

36. KOONSE, B.; BURKHARDT, W.; CHIRTEL, S.; HOSKIN, G. P. Salmonella and the sanitary quality of aquacultured shrimp. Journal of Food Protection, v. 68, n. 12, p. 2527-2532, 2005. 